\title{
Simultaneous, Delayed and Liver-First Hepatic Resections for Synchronous Colorectal Liver Metastases: A Systematic Review and Network Meta-Analysis
}

\author{
Paschalis Gavriilidis $^{\mathrm{a}, \mathrm{e}}$, Konstantinos Katsanos ${ }^{\mathrm{b}}$, Robert P. Sutcliffe ${ }^{\mathrm{a}}$, \\ Constantinos Simopoulos ${ }^{\mathrm{c}}$, Daniel Azoulay ${ }^{\mathrm{d}}$, Keith J. Roberts ${ }^{\mathrm{a}}$
}

\begin{abstract}
Background: Systematic reviews and meta-analyses that compare simultaneous, delayed and liver-first approach for synchronous colorectal liver metastases have found no significant differences. The aim of this study was to determine the best treatment strategy on the basis of effect sizes and the probabilities of treatment ranking by using a network meta-analysis. Moreover, first-time pairwise and network meta-analyses were used to estimate the existing evidence, and their results were compared to detect any discrepancies between them.
\end{abstract}

Methods: Systematic review, pairwise meta-analysis and network meta-analysis were performed. The primary and secondary outcomes were 5-year overall survival and postoperative major morbidity, respectively.

Results: No significant differences in long-term survival and major morbidity were found amongst the three approaches. The hazard ratios (95\% confidence interval) for 5-year overall survival for the simultaneous, delayed and liver-first approaches were $0.93(0.69-1.24, \mathrm{P}=$ $0.613), 0.97(0.87-1.07, \mathrm{P}=0.596)$ and $0.90(0.67-1.22, \mathrm{P}=0.499)$, respectively. Moreover, the liver-first approach with a surface under the cumulative ranking area score of $89 \%$ was ranked as the potentially best treatment option based on probabilities of treatment ranking.

Conclusions: On the basis of the relative ranking of treatments, the liver-first approach ranked first, followed by the delayed and simultaneous approaches. Therefore, a three-arm randomized controlled trial that compares the liver-first, simultaneous and delayed approaches

Manuscript submitted May 25, 2019, accepted June 17, 2019

aDepartment of Hepato-Pancreato-Biliary and Liver Transplant Surgery, Queen Elizabeth University Hospitals Birmingham NHS Foundation Trust, Birmingham B15 2TH, UK

bDepartment of Interventional Radiology, Patras University Hospital, School of Medicine, Rion, 26504 Patras, Greece

${ }^{c}$ The 2nd Department of Surgery, Medical School, Democritus University of Thrace, 68100 Alexandroupolis, Greece

${ }^{\mathrm{d}}$ Department of Hepato-Pancreato-Biliary and Liver Transplantation, Henri Mondor University Hospital, 94010 Creteil, France

${ }^{\mathrm{e} C}$ Corresponding Author: Paschalis Gavriilidis, Queen Elizabeth University Hospitals Birmingham NHS Foundation Trust, Mindelsohn Way, Birmingham B15 2TH, UK. Email: pgavrielidis@yahoo.com

doi: https://doi.org/10.14740/jocmr3887 needs to shed further light as to which is the best treatment option.

Keywords: Synchronous colorectal liver metastases; Simultaneous; Delayed; Liver-first; Liver resection; Hepatectomy

\section{Introduction}

Compared with patients with metachronous metastases, those with synchronous colorectal liver metastases (SCRLM) represent the cohort with the worst prognosis [1]; however, longterm survival can be achieved [2].

Three principal treatment strategies are available for these patients with potentially resectable SCRLM, namely classic or delayed, simultaneous and liver-first approaches [3]. However, the optimal sequence of colorectal resection has not been clearly defined and remains controversial [4]. The current evidence based on systematic reviews and conventional metaanalysis has been inconclusive [4].

Network meta-analysis is an evidence synthesis tool that can compare three or more interventions or treatments. It is particularly useful when the comparative effectiveness of interventions of numerous studies needs to be compared with multiple treatments and mixed treatment comparisons. Another advantage of network meta-analysis to the traditional metaanalysis is that it can be used to estimate not only direct but also indirect evidence. Direct evidence can be estimated from head-to-head comparisons between interventions performed within individual studies. On the other hand, indirect evidence is based on comparisons between interventions inferred from the network via a common comparator study [5].

The aim of this study was to determine the probability percentage of the three possible strategies to treat SCRLM and rank these by using the network meta-analysis. Moreover, for the first time, the existing evidence was estimated and compared with both pairwise and network meta-analyses.

\section{Materials and Methods}

The PRISMA Statement checklist for reporting systematic reviews and meta-analyses was followed in this study [6]. 


\section{Literature search}

Using both free texts and MESH terms (synchronous colorectal liver metastases; resectable; liver-first hepatectomy and liver resection; simultaneous hepatectomy and liver resection; delayed hepatectomy and liver resection), a systematic literature search was performed in the Medline, Embase, PubMed and Google Scholar databases from their inception until March 2019. Abstracts were selected. References of the retrieved articles were checked manually for further studies. Any discrepancies between the authors were resolved by consensus discussion among the authors.

\section{Study selection and inclusion and exclusion criteria}

Only studies that compared 1) simultaneous and delayed, 2) liverfirst and simultaneous and 3) liver-first and delayed hepatic resections for SCRLM were included in the review. Time, language, and region restrictions were not applied in the systematic review.

\section{Data extraction and outcomes}

Two researchers (PG and KK) independently extracted the following summary data for the included studies: name of authors, study design and time period; number of patients included for simultaneous, delayed and liver-first hepatic resections; age; sex; colonic primaries; patients treated with neoadjuvant and adjuvant therapies; major hepatectomies.

The primary and secondary outcomes were long-term overall survival and postoperative major morbidity (ClavienDindo III and IV), respectively [7].

\section{Statistical analysis}

The methodological quality of all the included studies was assessed using the validated Newcastle-Ottawa scale (NOS) [8]. Studies with scores of $\geq 7$ were considered of high quality.

First, a pairwise meta-analysis was performed for studies that compared two surgical approaches. Subsequently, a network meta-analysis was conducted to compare simultaneous, delayed and liver-first approaches. Statistical analysis was conducted using Stata version 15 software (Stata Corp LP, College Station, TX, USA). Dichotomous variables were analyzed on the basis of odds ratios (ORs) with $95 \%$ confidence intervals (CIs). Long-term survival was analyzed by combining the hazard ratios (HRs) and 95\% CIs from the included studies. These were rarely reported and so were estimated using the method described by Parmar et al [9], where this was possible. For studies that reported the numbers at risk, these were combined with either the quoted survival rates or values read from enlarged plots of the Kaplan-Meier curves to produce the estimates. Where numbers at risk were not quoted, constant censoring over the follow-up period was assumed in the estimation.

In all the analyses, the point estimate was considered significant at $\mathrm{P}$ values of $<0.05$. Publication bias was examined for the primary outcomes by assessing visual asymmetry on a funnel plot [10].

Network meta-analysis was performed using hierarchical random-effects models [11]. A fixed-effects model was also used to estimate if any discrepancy could be demonstrated between the results of the two models. Quantitative data synthesis of the connected network of the studies was conducted with the software package WinBUGS version 1.4.3 (MRC Biostatistics Unit, Cambridge, UK) [12]. The pooled estimates were obtained using the Markov chain Monte Carlo method. Minimally informative priors with vague normal prior distributions were used [12]. For each model, 200,000 simulations were generated for the two sets of different initial values, and the first 5,000 simulations were discarded as the burn-in period. The BrooksGelman-Rubin statistics was used for the assessment of convergence [12]. The point estimate was estimated as the median of the posterior distribution based on 200,000 simulations; the corresponding $95 \%$ credible intervals were obtained using the 2.5th and 97.5th percentiles of the posterior distribution, which can be interpreted in a similar way as $95 \%$ CIs [13]. The inconsistency and heterogeneity of the direct and indirect evidence for the three surgical approaches were estimated.

The $95 \%$ prediction intervals were calculated with a random-effects model and reported to assess further statistical heterogeneity. They demonstrated an effect variance among studies and predicted a more conservative summary treatment effect for a future similar trial $[14,15]$.

The node splitting method was used to calculate the inconsistency of the model, which separated evidence into direct and indirect; then, the agreement between the two was evaluated and reported with diagnostic information criterion (DIC) and effect estimates of direct and indirect evidence $[14,15]$.

To measure the treatment efficacy, the probability of each treatment being the best was calculated. Plots of cumulative ranking probabilities (rankograms) were created to demonstrate how each treatment ranks against each other in terms of being the first, second, or third best. The larger the area under the cumulative probability ranking curve, the better the treatment than the rest [16].

\section{Definitions}

Major hepatectomy was defined as a liver resection of $\geq 3$ segments. Postoperative major morbidity was classified in accordance with the Clavien-Dindo classification [7].

\section{Results}

\section{Study selection, characteristics and NOS}

Thirty-two retrospective studies were selected from among 1,165 studies [17-48] (Fig. 1), of which 22 (68.75\%) were of high quality, with an NOS score of $\geq 7$ (Table 1) $[19,21,22$, $24,25,27-29,33,34,36-42,44-48]$.

No statistically significant difference was found in the demographic characteristics among the three approaches and in 


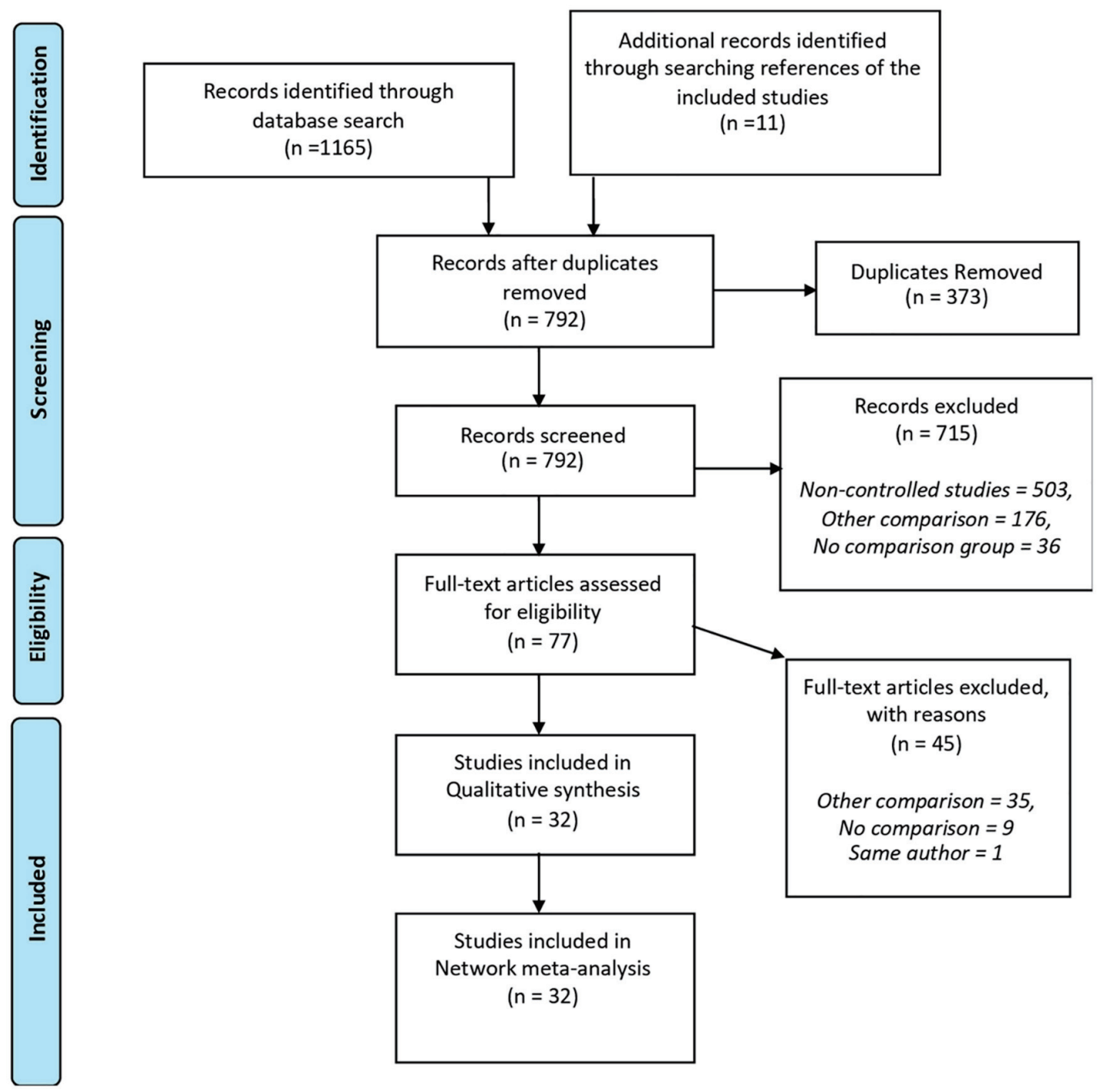

Figure 1. Flow diagram of the search strategy and selection of studies.

the proportion of colon primaries and rectal tumors between the simultaneous and delayed cohorts $(\mathrm{P}=0.521)$. However, the number of rectal tumors was significantly higher in the liverfirst cohort $(\mathrm{P}=0.001)[35,40,41,47,48]$ than in the other cohorts. A significantly higher number of patients in the delayed and liver-first cohorts than in the simultaneous cohort underwent a major hepatic resection $(\mathrm{P}<0.001$; Table 1$)$. The proportion of patients with bilobar distribution of metastases was significantly lower in the simultaneous cohort than in the delayed and liverfirst cohorts $(\mathrm{P}<0.001)$ [19-21, 26-29, 31, 37, 39-41, 44-48].

\section{Results from the pairwise meta-analysis of primary and secondary outcomes}

No significant difference in long-term overall survival was found in the three head-to-head comparisons as follows: simultaneous versus delayed (HR: $0.97,95 \% \mathrm{CI}$ : $0.88-1.08, \mathrm{P}=$
$0.60, \mathrm{I}^{2}=0 \%$ ), liver-first versus simultaneous (HR: $0.90,95 \%$ CI: $\left.0.55-1.47, \mathrm{P}=0.67, \mathrm{I}^{2}=0 \%\right)$ and liver-first versus delayed approaches (HR: 0.88, 95\% CI: $0.56-1.39, \mathrm{P}=0.59, \mathrm{I}^{2}=45 \%$; Supplementary Fig. 1, www.jocmr.org).

Similarly, no evidence of a significant difference was found between the simultaneous and delayed (OR: 1.06, 95\% CI: $0.9-1.25, \mathrm{P}=0.29 ; \mathrm{I}^{2}=41 \%$ ), liver-first and simultaneous (OR: 0.58, 95\% CI: $0.15-2.19 ; \mathrm{I}^{2}=0 \%, \mathrm{P}=0.734$ ) and liverfirst and delayed approaches (OR: $0.56,95 \%$ CI: 0.21 - 1.52; $\mathrm{I}^{2}=0 \%, \mathrm{P}=0.567$ ) with respect to major morbidity (ClavienDindo III and IV; Supplementary Fig. 2, www.jocmr.org).

\section{Results from the network meta-analysis of primary and secondary outcomes}

In the present study, the Bayesian network meta-analysis included 2,235 patients in the simultaneous cohort, 3,824 in the 
Table 1. Included Studies, Patient Demographics and Characteristics, and Newcastle-Ottawa Scale (NOS) Score [17-48]

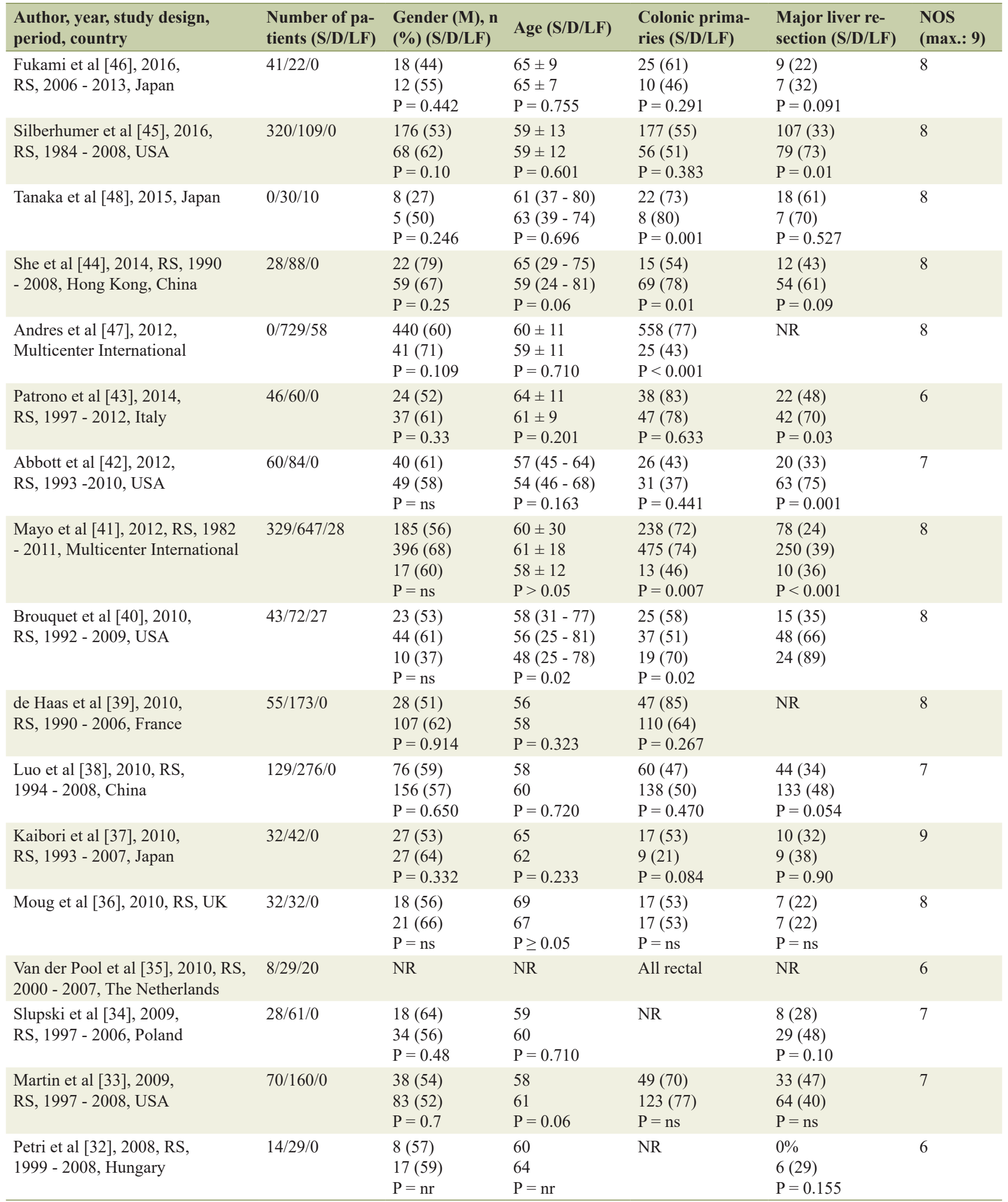


Table 1. Included Studies, Patient Demographics and Characteristics, and Newcastle-Ottawa Scale (NOS) Score [17-48] - (continued)

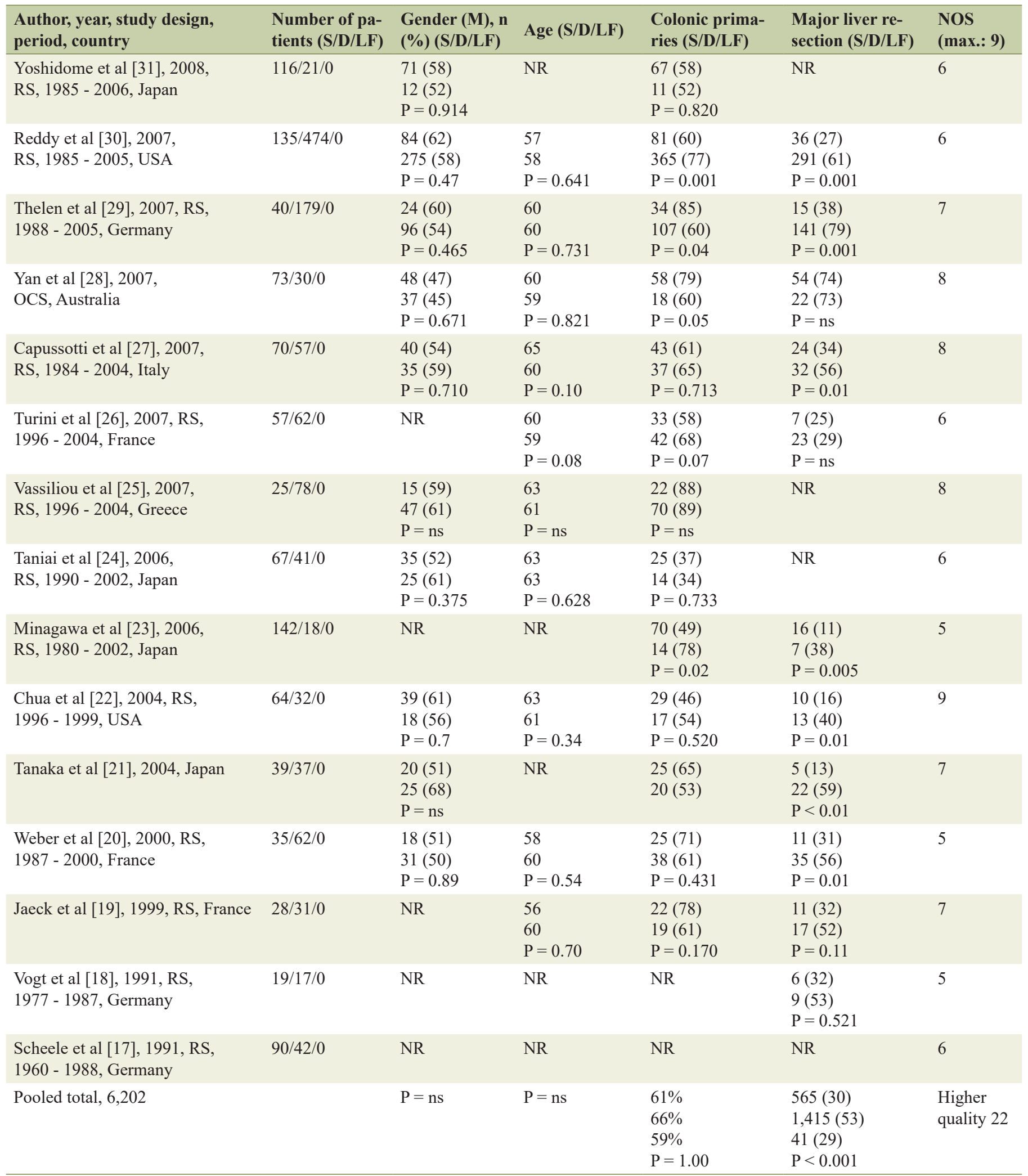

S: simultaneous; D: delayed; LF: liver-first; ns: non-significant; NR: not reported; NOS: Newcastle-Ottawa scale; RS: retrospective study. 


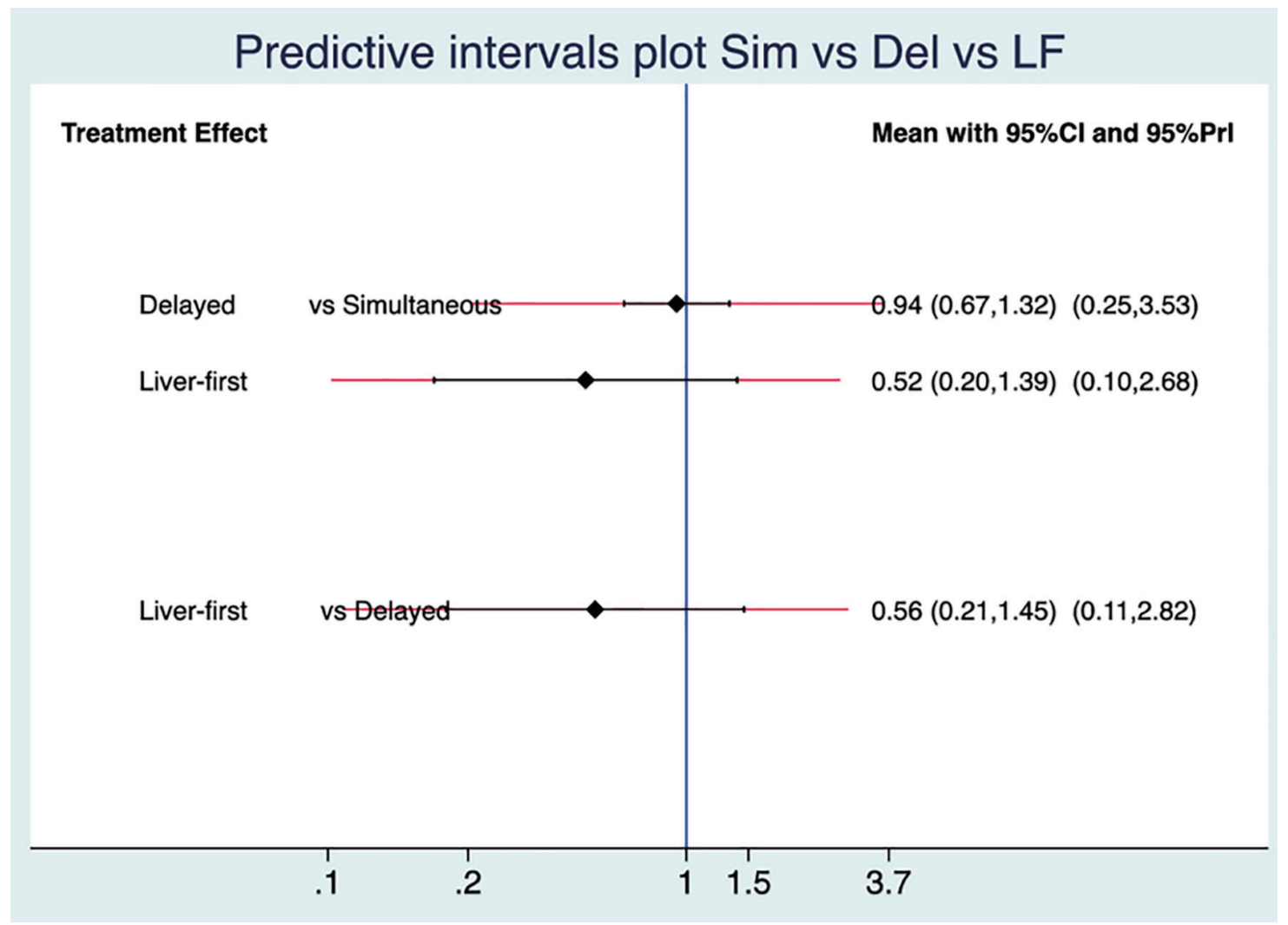

Figure 2. Predictive interval plot of the three surgical approaches. The blue line represents the line of no effect (OR: 1). The black and red lines denote confidence and predictive intervals, respectively. OR: odds ratio.

delayed cohort and 143 in the liver-first cohort. The network of evidence of the three surgical approaches was demonstrated with a closed loop (triangle; Supplementary Fig. 3, www. jocmr.org).

Patient long-term survival was similar between the simultaneous, delayed, and liver-first approaches of the network of evidence (HR: 0.93, 95\% CI: $0.69-1.24, \mathrm{P}=0.613$; HR: 0.97, 95\% CI: $0.87-1.07, \mathrm{P}=0.596$; and HR: $0.90,95 \% \mathrm{CI}: 0.67-1.22$, $\mathrm{P}=0.499$, respectively). Moreover, the evaluation of inconsistency using loop-specific heterogeneity was estimated to be nonsignificant (relative OR (ROR): $1.185,95 \%$ CI: 1.00 - 10.54, P= 0.974; $\tau^{2}=0.288$; Supplementary Fig. 4, www.jocmr.org).

Similar to the pairwise meta-analysis, the network metaanalysis showed no differences in postoperative major morbidity amongst the three surgical approaches. The OR and CIs for the comparison between the simultaneous and delayed approaches were 0.94 and $0.67-1.32$; between the liver-first and simultaneous approaches, 0.52 and $0.20-1.39$; and between the liver-first and delayed approaches were 0.57 and $0.21-1.45$, respectively. Their predictive intervals $(95 \% \mathrm{PrI})$ for similar future trials were also non-significant $(0.25-3.53$, $0.10-2.68$ and 0.11 - 2.82, respectively; Fig. 2).

\section{Ranking probabilities for competing treatments}

Rankograms of the cumulative ranking probabilities of the best approach based on overall survival and major morbidity were created. The best surgical approach was the one with the largest area under the cumulative probability ranking curve. All approaches were compared with both estimated and predictive probabilities. Comparing the treatment relative ranking of estimated probabilities, the liver-first group was the best, with a surface under cumulative ranking area (SUCRA) of $90.3 \%$; the delayed group was second, with an SUCRA of $36.6 \%$; and the simultaneous group was third, with an SUCRA of $23.1 \%$ (Fig. 3).

The ranking of the three surgical approaches according to the predictive probabilities was the same. However, the SUCRA decreased for the liver-first group from $90.3 \%$ to $78.5 \%$; on the contrary, the SUCRA of the simultaneous group increased from $23.1 \%$ to $33.1 \%$ and that for the delayed group slightly increased from $36.6 \%$ to $38.5 \%$ (Fig. 3 ).

\section{Sensitivity, heterogeneity, inconsistency analysis and pub- lication bias}

No significant discrepancies were found when comparing the $95 \%$ CI with the $95 \%$ PrI of all pairwise comparisons in the present Bayesian network meta-analysis (Fig. 3). The evaluation of inconsistency using loop-specific heterogeneity was estimated to be non-significant (ROR: 1.185 , 95\% CI: 1.00 - 10.54; Supplementary Fig. 4, www.jocmr.org). In addition, 


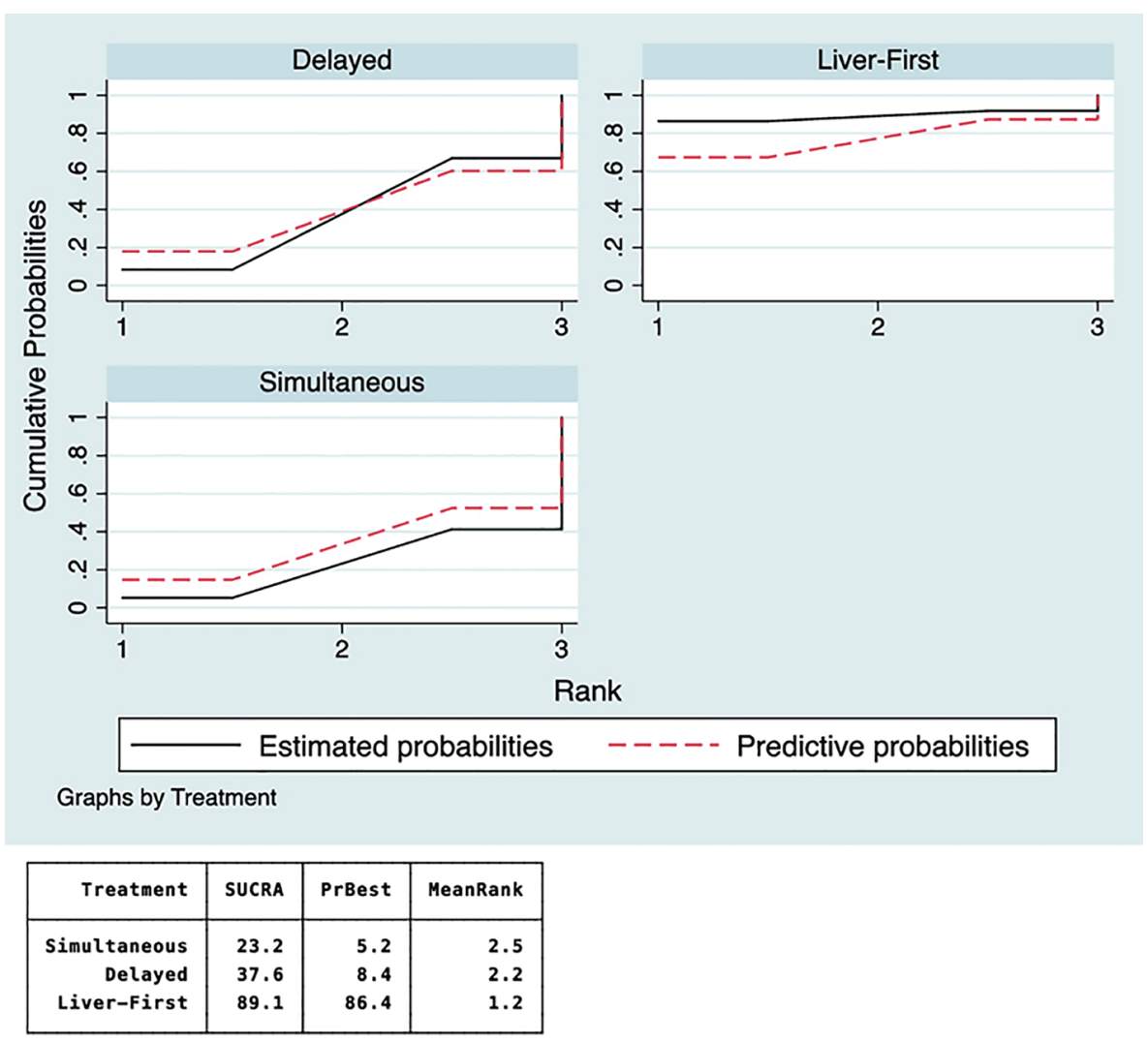

'reatment Relative Ranking of Predictive probabilities

\begin{tabular}{|r|r|r|r|}
\hline Treatment & SUCRA & PrBest & MeanRank \\
\hline Simultaneous & 33.6 & 14.7 & 2.3 \\
Delayed & 39.0 & 17.8 & 2.2 \\
Liver-First & 77.4 & 67.4 & 1.5 \\
\hline
\end{tabular}

Figure 3. Rankograms of probability of each treatment being first, second, or third. The liver-first approach has an $86 \%$ probability of being the best, followed by the delayed and simultaneous approaches, with $8 \%$ and $5 \%$ probability, respectively. SUCRA: surface under the cumulative ranking area.

the random-effects standard deviation of 0.0493 and timeseries standard error of 0.0008 proved the consistency of the model. First, the arbitrary starting values did not have an undue influence on the sampling process. Second, the quantities of interest were estimated with sufficient accuracy. The timeseries plot demonstrated a converged chain that contained sufficient information for accurate inferences; the potential scale reduction factor (PSRF) reached stable values of $<1.01$, and the series plot of the estimation accuracy showed smooth density and tapering off of the extreme values in the tails. Furthermore, no inconsistency of the model was found using the node-splitting method. An agreement between the direct and indirect evidence amongst the three node-split models was found (Fig. 4).

A comparison-adjusted funnel plot of bias showed some indication of publication bias, with asymmetry amongst the smaller studies. However, because of the low weighting of these studies, the effect of this potential bias on the results was negligible (Fig. 5).

\section{Discussion}

The network meta-analysis in this study demonstrates that no currently used strategy to resect SCRLM has superiority over another in terms of survival or perioperative complications. The Bayesian computation with fixed-effects model did not show any discrepancies with the random-effects model. In a recent meta-analysis of a pairwise comparison of simultaneous and delayed approaches, we reported an absence of evidence of significant differences in long-term survival and safety [49].

In the present study, for the first time, pairwise and network meta-analyses were simultaneously conducted for the three surgical approaches. The advantages, disadvantages, and limitations of the three treatment strategies remain con- 


\begin{tabular}{|c|c|c|c|}
\hline Model name & DIC ? & \multicolumn{2}{|c|}{ Effect estimates } \\
\hline Nodesplit model (1 - 2) & 21.643 & $\begin{array}{l}\text { Direct } \\
\text { Indirect } \\
\text { Consistency }\end{array}$ & $\begin{array}{l}-0.032(-0.143,0.073) \\
-0.021(-0.627,0.573) \\
-0.033(-0.150,0.072)\end{array}$ \\
\hline Nodesplit model (1 - 3) & 21.633 & $\begin{array}{l}\text { Direct } \\
\text { Indirect } \\
\text { Consistency }\end{array}$ & $\begin{array}{l}-0.107(-0.596,0.396) \\
-0.123(-0.472,0.246) \\
-0.105(-0.380,0.175)\end{array}$ \\
\hline Nodesplit model (2 - 3) & 21.552 & $\begin{array}{l}\text { Direct } \\
\text { Indirect } \\
\text { Consistency }\end{array}$ & $\begin{array}{l}-0.082(-0.424,0.253) \\
-0.049(-0.575,0.414) \\
-0.067(-0.341,0.209)\end{array}$ \\
\hline
\end{tabular}

\section{1-2: simultaneous vs delayed, 1-3: simultaneous vs liver-first, 2-3: delayed vs liver-first}

Figure 4. Node-split model (1 - 2): simultaneous vs. delayed; node-split model (1 - 3): simultaneous vs. liver-first; node-split model (2 - 3): delayed vs. liver-first. An agreement between direct and indirect evidence exists. The DIC demonstrates goodness of fit of the model. DIC: deviance information criterion.

troversial [4]. The liver-first approach was ranked as the best treatment with respect to its relative efficacy on the basis of 5 -year overall survival outcomes and postoperative compli- cation rate. It is interesting that the treatment relative ranking of the predictive probabilities demonstrated that as the liver-first approach will be applied more often in the future,

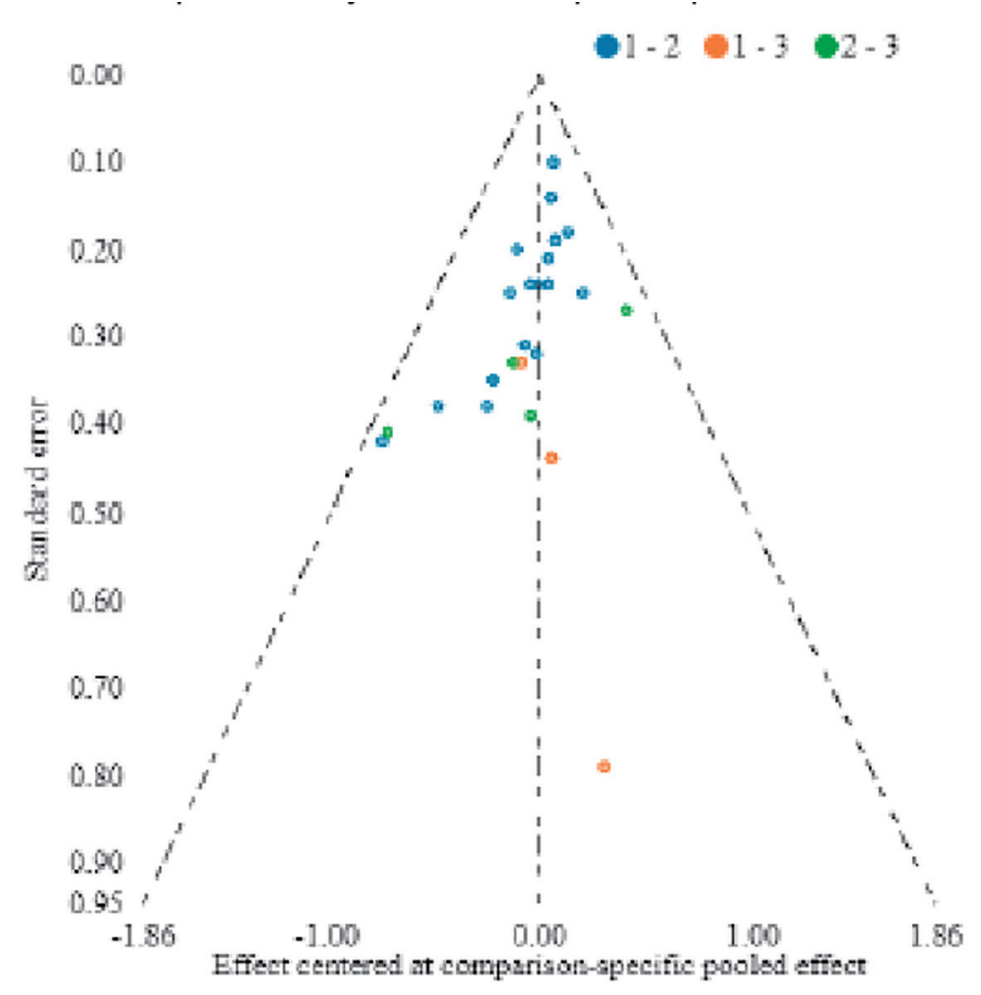

1-2: simultaneous vs delayed, 1-3: simultaneous vs liver-first, 2-3: delayed vs liver-first

Figure 5. Comparison-adjusted funnel plot of publication bias. 
its SUCRA will decrease from $89 \%$ to $77 \%$, but it would still represent the better treatment option than the other two. The SUCRA score expresses the percentage of effectiveness or safety of each treatment as compared with that of an "ideal" treatment that always rank first without uncertainty [16]. The same method showed that the simultaneous and delayed approaches can be extensively and slightly improved, respectively. In general, the ranking will remain the same in future trials. Network meta-analysis offers clinicians this new tool. Clinical decisions about the choice of the best treatment strategy can be suggested on the basis of the probabilities of treatment ranking.

To the authors' best knowledge, this is the biggest network meta-analysis, which included 32 studies. The previous study included 18 studies and had a principal methodological weakness of estimating survival with OR [49]. Survival by default is estimated with HR, and if the authors of the included studies rarely report them, then they can be estimated with the method described by Parmar $[9,50,51]$.

\section{Conclusion}

The evidence from this study supports the application of any of the three surgical strategies, provided they are applied to carefully selected patients. The principal limitation of this study is that it included only retrospective studies and a small number of studies that compared the liver-first approach with other approaches. Moreover, readers should also take into account that creation of rankograms based on probabilistic statistics should be interpreted accordingly. Therefore, their results should be compared with those of the conventional frequentist metaanalysis and adequate conclusions should be made.

In addition, a topic that needs special attention and further investigation is the surveillance strategy of SCRLM. More than $20 \%$ of patients with intensive surveillance were eligible for redo hepatic resections as compared with patients with less-intensive surveillance. Moreover, they demonstrated more survival benefits [52]. Therefore, future randomized controlled trials with predefined surgical outcome parameters, short- and long-term mortality rates, follow-up of 5 - 10 years, and moreintensive surveillance may help further elucidate the efficacy of the three surgical procedures.

\section{Acknowledgments}

Not applicable.

\section{Financial Support}

None to declare.

\section{Conflict of Interest}

All the authors declare that they have no conflict of interest.

\section{Informed Consent}

This study does not contain any studies with human participants or animals performed by any of the authors.

\section{Author Contributions}

PG: study concept and design; acquisition of data; analysis and interpretation of data; drafting the manuscript; statistical analysis. KK: analysis and interpretation of data; drafting the manuscript. RPS: acquisition of data; analysis and interpretation of data; drafting the manuscript. CC: analysis and interpretation of data; drafting the manuscript. DA: acquisition of data; analysis and interpretation of data; drafting the manuscript. KJR: acquisition of data; analysis and interpretation of data; drafting the manuscript; study supervision.

\section{References}

1. Manfredi S, Lepage C, Hatem C, Coatmeur O, Faivre J, Bouvier AM. Epidemiology and management of liver metastases from colorectal cancer. Ann Surg. 2006;244(2):254-259.

2. Rees M, Tekkis PP, Welsh FK, O'Rourke T, John TG. Evaluation of long-term survival after hepatic resection for metastatic colorectal cancer: a multifactorial model of 929 patients. Ann Surg. 2008;247(1):125-135.

3. Mentha G, Majno PE, Andres A, Rubbia-Brandt L, Morel $\mathrm{P}$, Roth AD. Neoadjuvant chemotherapy and resection of advanced synchronous liver metastases before treatment of the colorectal primary. Br J Surg. 2006;93(7):872-878.

4. Adam R, de Gramont A, Figueras J, Kokudo N, Kunstlinger F, Loyer E, Poston G, et al. Managing synchronous liver metastases from colorectal cancer: a multidisciplinary international consensus. Cancer Treat Rev. 2015;41(9):729-741.

5. Palmer TM, Sterne AC (editors). Meta-analysis in Stata: An update collection from the Stata journal (second edition). Stata Press. 2016.

6. Moher D, Liberati A, Tetzlaff J, Altman DG, The PRISMA Group. Preferred reporting items for systematic reviews and meta-analyses: the PRISMA statement. PLoS Med. 2009;6(7):e1000097.

7. Clavien PA, Barkun J, de Oliveira ML, Vauthey JN, Dindo D, Schulick RD, de Santibanes E, et al. The ClavienDindo classification of surgical complications: five-year experience. Ann Surg. 2009;250(2):187-196.

8. Wells GA, Shea B, O'Connell D, et al. The NewcastleOttawa scale (NOS) for assessing the quality of nonrandomised studies in meta-analyses. 2011, Available at: http://www.ohri.ca/programs/clinical_epidemiology/oxford.asp. Accessed.

9. Parmar MK, Torri V, Stewart L. Extracting summary statistics to perform meta-analyses of the published literature for survival endpoints. Stat Med. 1998;17(24):28152834 . 
10. Egger M, Davey Smith G, Schneider M, Minder C. Bias in meta-analysis detected by a simple, graphical test. BMJ. 1997;315(7109):629-634.

11. Lu G, Ades AE. Combination of direct and indirect evidence in mixed treatment comparisons. Stat Med. 2004;23(20):3105-3124.

12. Ades AE, Sculpher M, Sutton A, Abrams K, Cooper N, Welton N, Lu G. Bayesian methods for evidence synthesis in cost-effectiveness analysis. Pharmacoeconomics. 2006;24(1):1-19.

13. Wandel S, Juni P, Tendal B, Nuesch E, Villiger PM, Welton NJ, Reichenbach S, et al. Effects of glucosamine, chondroitin, or placebo in patients with osteoarthritis of hip or knee: network meta-analysis. BMJ. 2010;341:c4675.

14. Dias S, Sutton AJ, Welton NJ, Ades AE. Evidence synthesis for decision making 3: heterogeneity - subgroups, meta-regression, bias, and bias-adjustment. Med Decis Making. 2013;33(5):618-640.

15. Guddat C, Grouven U, Bender R, Skipka G. A note on the graphical presentation of prediction intervals in randomeffects meta-analyses. Syst Rev. 2012;1:34.

16. Salanti G, Ades AE, Ioannidis JP. Graphical methods and numerical summaries for presenting results from multiple-treatment meta-analysis: an overview and tutorial. J Clin Epidemiol. 2011;64(2):163-171.

17. Scheele J, Stangl R, Altendorf-Hofmann A, Gall FP. Indicators of prognosis after hepatic resection for colorectal secondaries. Surgery. 1991;110(1):13-29.

18. Vogt P, Raab R, Ringe B, Pichlmayr R. Resection of synchronous liver metastases from colorectal cancer. World J Surg. 1991;15(1):62-67.

19. Jaeck D, Bachellier P, Weber JC, Boudjema K, Mustun A, Paris F, Schaal JC, et al. [Surgical strategy in the treatment of synchronous hepatic metastases of colorectal cancers. Analysis of a series of 59 operated on patients]. Chirurgie. 1999;124(3):258-263.

20. Weber JC, Bachellier P, Oussoultzoglou E, Jaeck D. Simultaneous resection of colorectal primary tumour and synchronous liver metastases. Br J Surg. 2003;90(8):956962.

21. Tanaka K, Shimada H, Matsuo K, Nagano Y, Endo I, Sekido H, Togo S. Outcome after simultaneous colorectal and hepatic resection for colorectal cancer with synchronous metastases. Surgery. 2004;136(3):650-659.

22. Chua HK, Sondenaa K, Tsiotos GG, Larson DR, Wolff BG, Nagorney DM. Concurrent vs. staged colectomy and hepatectomy for primary colorectal cancer with synchronous hepatic metastases. Dis Colon Rectum. 2004;47(8):1310-1316.

23. Minagawa M, Yamamoto J, Miwa S, Sakamoto Y, Kokudo N, Kosuge T, Miyagawa S, et al. Selection criteria for simultaneous resection in patients with synchronous liver metastasis. Arch Surg. 2006;141(10):1006-1012; discussion 1013.

24. Taniai N, Yoshida H, Mamada Y, Matsumoto S, Mizuguchi Y, Suzuki H, Furukawa K, et al. Outcome of surgical treatment of synchronous liver metastases from colorectal cancer. J Nippon Med Sch. 2006;73(2):82-88.

25. Vassiliou I, Arkadopoulos N, Theodosopoulos T, Fragulid- is G, Marinis A, Kondi-Paphiti A, Samanides L, et al. Surgical approaches of resectable synchronous colorectal liver metastases: timing considerations. World J Gastroenterol. 2007;13(9):1431-1434.

26. Turrini O, Viret F, Guiramand J, Lelong B, Bege T, Delpero JR. Strategies for the treatment of synchronous liver metastasis. Eur J Surg Oncol. 2007;33(6):735-740.

27. Capussotti L, Vigano L, Ferrero A, Lo Tesoriere R, Ribero D, Polastri R. Timing of resection of liver metastases synchronous to colorectal tumor: proposal of prognosis-based decisional model. Ann Surg Oncol. 2007;14(3):1143-1150.

28. Yan TD, Chu F, Black D, King DW, Morris DL. Synchronous resection of colorectal primary cancer and liver metastases. World J Surg. 2007;31(7):1496-1501.

29. Thelen A, Jonas S, Benckert C, Spinelli A, Lopez-Hanninen E, Rudolph B, Neumann U, et al. Simultaneous versus staged liver resection of synchronous liver metastases from colorectal cancer. Int J Colorectal Dis. 2007;22(10):1269-1276.

30. Reddy SK, Pawlik TM, Zorzi D, Gleisner AL, Ribero D, Assumpcao L, Barbas AS, et al. Simultaneous resections of colorectal cancer and synchronous liver metastases: a multi-institutional analysis. Ann Surg Oncol. 2007;14(12):3481-3491.

31. Yoshidome H, Kimura F, Shimizu H, Ohtsuka M, Kato A, Yoshitomi H, Furukawa K, et al. Interval period tumor progression: does delayed hepatectomy detect occult metastases in synchronous colorectal liver metastases? J Gastrointest Surg. 2008;12(8):1391-1398.

32. Petri A, Hohn J, Balogh A, Kovach K, Andrasi L, Lazar G. [Surgical treatment of liver metastasis in colorectal cancer with simultaneous liver resection]. Magy Onkol. 2010;54(2):125-128.

33. Martin RC, 2nd, Augenstein V, Reuter NP, Scoggins CR, McMasters KM. Simultaneous versus staged resection for synchronous colorectal cancer liver metastases. J Am Coll Surg. 2009;208(5):842-850; discussion 850-842.

34. Slupski M, Wlodarczyk Z, Jasinski M, Masztalerz M, Tujakowski J. Outcomes of simultaneous and delayed resections of synchronous colorectal liver metastases. Can J Surg. 2009;52(6):E241-244.

35. van der Pool AE, de Wilt JH, Lalmahomed ZS, Eggermont AM, Ijzermans JN, Verhoef C. Optimizing the outcome of surgery in patients with rectal cancer and synchronous liver metastases. Br J Surg. 2010;97(3):383-390.

36. Moug SJ, Smith D, Leen E, Roxburgh C, Horgan PG. Evidence for a synchronous operative approach in the treatment of colorectal cancer with hepatic metastases: a case matched study. Eur J Surg Oncol. 2010;36(4):365-370.

37. Kaibori M, Iwamoto S, Ishizaki M, Matsui K, Saito T, Yoshioka K, Hamada Y, et al. Timing of resection for synchronous liver metastases from colorectal cancer. Dig Dis Sci. 2010;55(11):3262-3270.

38. Luo Y, Wang L, Chen C, Chen D, Huang M, Huang Y, Peng J, et al. Simultaneous liver and colorectal resections are safe for synchronous colorectal liver metastases. J Gastrointest Surg. 2010;14(12):1974-1980.

39. de Haas RJ, Adam R, Wicherts DA, Azoulay D, Bismuth 
H, Vibert E, Salloum C, et al. Comparison of simultaneous or delayed liver surgery for limited synchronous colorectal metastases. Br J Surg. 2010;97(8):1279-1289.

40. Brouquet A, Mortenson MM, Vauthey JN, RodriguezBigas MA, Overman MJ, Chang GJ, Kopetz S, et al. Surgical strategies for synchronous colorectal liver metastases in 156 consecutive patients: classic, combined or reverse strategy? J Am Coll Surg. 2010;210(6):934-941.

41. Mayo SC, Pulitano C, Marques H, Lamelas J, Wolfgang CL, de Saussure W, Choti MA, et al. Surgical management of patients with synchronous colorectal liver metastasis: a multicenter international analysis. J Am Coll Surg. 2013;216(4):707-716; discussion 716-708.

42. Abbott DE, Cantor SB, Hu CY, Aloia TA, You YN, Nguyen S, Chang GJ. Optimizing clinical and economic outcomes of surgical therapy for patients with colorectal cancer and synchronous liver metastases. J Am Coll Surg. 2012;215(2):262-270.

43. Patrono D, Paraluppi G, Perino M, Palisi M, Migliaretti G, Berchialla P, Romagnoli R, et al. Posthepatectomy liver failure after simultaneous versus staged resection of colorectal cancer and synchronous hepatic metastases. G Chir. 2014;35(3-4):86-93.

44. She WH, Chan AC, Poon RT, Cheung TT, Chok KS, Chan SC, Lo CM. Defining an optimal surgical strategy for synchronous colorectal liver metastases: staged versus simultaneous resection? ANZ J Surg. 2015;85(11):829833.

45. Silberhumer GR, Paty PB, Denton B, Guillem J, Gonen M, Araujo RLC, Nash GM, et al. Long-term oncologic outcomes for simultaneous resection of synchronous metastatic liver and primary colorectal cancer. Surgery. 2016;160(1):67-73.
46. Fukami Y, Kaneoka Y, Maeda A, Takayama Y, Onoe S, Isogai M. Simultaneous resection for colorectal cancer and synchronous liver metastases. Surg Today. 2016;46(2):176-182.

47. Andres A, Toso C, Adam R, Barroso E, Hubert C, Capussotti L, Gerstel E, et al. A survival analysis of the liver-first reversed management of advanced simultaneous colorectal liver metastases: a LiverMetSurvey-based study. Ann Surg. 2012;256(5):772-778; discussion 778779.

48. Tanaka K, Murakami T, Matsuo K, Hiroshima Y, Endo I, Ichikawa Y, Taguri M, et al. Preliminary results of 'liverfirst' reverse management for advanced and aggressive synchronous colorectal liver metastases: a propensitymatched analysis. Dig Surg. 2015;32(1):16-22.

49. Kelly ME, Spolverato G, Le GN, Mavros MN, Doyle F, Pawlik TM, Winter DC. Synchronous colorectal liver metastasis: a network meta-analysis review comparing classical, combined, and liver-first surgical strategies. J Surg Oncol. 2015;111(3):341-351.

50. Gavriilidis P, Sutcliffe RP, Hodson J, Marudanayagam R, Isaac J, Azoulay D, Roberts KJ. Simultaneous versus delayed hepatectomy for synchronous colorectal liver metastases: a systematic review and meta-analysis. HPB (Oxford). 2018;20(1):11-19.

51. Khan KS, Kunz R, Kleijnen J, Antes G. Systematic reviews to support evidence-based medicine: how to review and apply findings of healthcare research. London: The Royal Society of Medicine Press Limited, 2003.

52. van der Stok EP, Spaander MCW, Grunhagen DJ, Verhoef C, Kuipers EJ. Surveillance after curative treatment for colorectal cancer. Nat Rev Clin Oncol. 2017;14(5):297315. 